\title{
STRATEGI PENINGKATAN KEBERLANJUTAN AGROINDUSTRI SAYUR POTONG STUDI KASUS DI PT SAYURAN SIAP SAJI
}

\section{STRATEGY FOR INCREASING SUSTAINABILITY OF FRESH-CUT VEGETABLE AGROINDUSTRY CASE STUDY IN PT SAYURAN SIAP SAJI}

\author{
Fransisca Susanti Wiryawan" ${ }^{\text {1* }}$, Marimin'), dan Taufik Djatna ${ }^{2)}$ \\ ${ }^{1)}$ Program Studi Manajemen Bisnis, Sekolah Bisnis Institut Pertanian Bogor \\ Jalan Pajajaran, Bogor, Jawa Barat. Indonesia, 16151 \\ E-mail: siscawiryawan@ymail.com \\ ${ }^{2)}$ Departemen Teknologi Industri Pertanian, Fakultas Teknologi Pertanian, Institut Pertanian Bogor \\ Makalah: Diterima 10 Juli 2018; Diperbaiki 11 Desember 2018; Disetujui 23 Januari 2018
}

\begin{abstract}
The development of fresh-cut vegetable agroindustry is a complicated case because it does not just involve production process, but it also involves various sustainability aspects. Therefore, it needs a data analysis method, namely Analytical Network Process Benefits Opportunities Costs Risks (ANP BOCR) by green productivity approach which applies environmentally friendly principle. The research aimed to determine priority strategy for increasing sustainability of fresh-cut vegetabe agroindustry. According to ANP BOCR method, there were four criteria which influence sustainability of fresh-cut vegetable, namely environment, technology, contract farming, and economy. The economy was the most dominant criteria. For increasing the sustainability of fresh-cut vegetable agroindustry, the best strategy was contract farming. It was appropriate with the three most influential subcriteria i.e. the increase of contract farmers' skill by farmer group, the increase of contract farmers' use, and the increase of company profit. The application of contract farming strategy is the movement of contract farming area to certain area located near the location of fresh-cut vegetable agroindustry and the accompaniment of contract farmer sustainably. The excellence of this research was the characteristic of strategic effect which means the application of strategy will give some impacts, namely decrease the carbon emission, the cost of transportation, and the defect of vegetable supply. By moving contract farming area to certain area located near the location of fresh-cut vegetable agroindustry,the accompaniment of contract farmer sustainably for increasing the contract farmers' skill in applying Good Agriculture Practice and Good Handling Practice will run intensively.
\end{abstract}

Keywords: ANP BOCR, fresh-cut vegetables, green productivity, sustainability

\section{ABSTRAK}

Pengembangan agroindustri sayur potong merupakan masalah yang kompleks karena tidak hanya melibatkan proses produksi sayur potong, tapi melibatkan berbagai aspek keberlanjutan sehingga memerlukan metode data analisis Analytic Network Process Benefits Opportunities Costs Risks (ANP BOCR) dengan pendekatan produktivitas hijau yang menerapkan prinsip ramah lingkungan. Tujuan dari penelitian ini ialahuntuk menentukan prioritas alternatif strategi peningkatan keberlanjutan agroindustri sayur potong. Berdasarkan metode ANP BOCR, keempat kriteria yang mempengaruhi keberlanjutan agroindustri sayur potong ialah lingkungan, teknologi, kemitraan, dan ekonomi. Kriteria ekonomi paling mempengaruhi keberlanjutan sayur potong. Strategi terbaik untuk peningkatan keberlanjutan agroindustri sayur potong ialah kemitraan. Hal tersebut sesuai dengan subkriteria yang paling mempengaruhi keberlanjutan agroindustri sayur potong, yaitu peningkatan keuntungan petani mitra, peningkatan keuntungan perusahaan, dan peningkatan keahlian petani mitra melalui kelompok tani. Penerapan strategi kemitraan ialah pemindahan area kemitraan ke area yang lebih dekat dengan lokasi agroindustri sayur potong dan pendampingan petani mitra berkelanjutan. Keunggulan penelitian ini ialah strategic effect yang berarti penerapan strategi tersebut akan memberikan dampak, seperti pengurangan emisi karbon, biaya transportasi, dan kerusakan bahan baku sayuran. Dengan area kemitraan yang lebih dekat dengan lokasi agroindustri sayur potong, pendampingan petani mitra secara berkelanjutan untuk meningkatkan keahlian petani mitra dalam menerapkan Good Agriculture Practice dan Good Handling Practice akan berjalan lebih intensif.

Kata kunci :ANP BOCR, keberlanjutan, produktivitas hijau, sayur potong

\section{PENDAHULUAN}

Keberlanjutan merupakan serangkaian institusi, kebijakan, dan faktor-faktor yang mendorong produktivitas suatu perusahaan dengan memastikan terjadinya keberlanjutan sosial, lingkungan (WEF, 2014), dan ekonomi (Sultan dan Saurabh, 2013). Untuk mencapai keberlanjutan berdasarkan konsep produktivitas hijau, dilakukan penentuan alternatif strategi yang tepat (Gonzalez et 
al., 2015).

Keunggulan Analytic Network Process (ANP) dalam pengambilan keputusan ialah bersifat obyektif (Persada et al., 2015) karena adanya hubungan antar elemen dalam satu cluster (interdependencies), hubungan antar elemen yang berbeda cluster (outerdependencies), dan umpan balik (feedbacks) (Gorener, 2012). ANP digunakan dalam pengambilan keputusan yang bersifat kompleks (Ikatrinasari et al., 2011) sehingga merupakan alat pengambil keputusan untuk mencapai keberlanjutan (Medel-Gonzalez et al., 2014) dengan meningkatkan kinerja (Murti et al., 2015). Penelitian ini menggunakan ANP BOCR yang unggul dalam mengatasi masalah yang rumit berdasarkan aspek benefits, opportunities, costs, dan risks (Dragoi, 2018). Beberapa studi yang menggunakan ANP BOCR (Jaafari et al., 2015; Sato et al., 2017; Xu et al., 2018).

Produk potong (fresh-cut) merupakan produk yang 100\% dapat dimanfaatkan konsumen karena mendapat perlakuan seperti pembuangan bagian yang busuk atau pun layu (trimming), pengupasan (peeling), pencucian, pemotongan (IFPA, 2017). Produk potong terdiri atas sayur potong, buah potong, salad potong, dan herba potong. Objek penelitian ini ialah sayur potong yang mendominasi produk makanan segar yang diolah secara minimal (Martin-Belloso dan Soliva-Fortuny, 2011). Konsumen industri sayur potong di Indonesia didominasi oleh restoran siap saji jika dibandingkan dengan retail supermarkets. Dengan sayur potong, restoran siap saji mengurangi biaya tenaga kerja, mengurangi ruang penyimpanan bahan baku, lebih efisien, dan tidak perlu menangani limbah padat. Berdasarkan hal tersebut, sayur potong merupakan agribisnis yang berpotensi menjanjikan di Indonesia yang memiliki pangsa pasar yang besar dengan jumlah penduduk mencapai 258,7 juta jiwa (BPS, 2017). Sebanyak 97,29\% penduduk Indonesia mengkonsumsi sayur sebesar $107 \mathrm{~g}$ per kapita per hari (BPS, 2016).

Penelitian ini merupakan studi kasus yang dilakukan di PT SSS, perusahaan sayur potong yang berlokasi di Desa Megamendung, Kabupaten Bogor. Agroindustri tersebut belum menerapkan produktivitas hijau sehingga tujuan penelitian ini ialah menentukan prioritas alternatif strategi peningkatan keberlanjutan sayur potong.

\section{METODE PENELITIAN}

Penelitian dimulai pada bulan Januari-Mei 2018. Metode penelitian menggunakan ANP BOCR untuk menentukan alternatif strategi terbaik (Gambar 1).

\section{Analytic Network Process-Benefits Opportunities Costs Risks}

Pemilihan alternatif strategi dengan metode

ANP berdasarkan kriteria utama menggunakan analisis BOCR (benefits, opportunities, costs, dan risks) dengan kriteria keberlanjutan berupa lingkungan, teknologi, kemitraan, dan ekonomi. Selanjutnya dilakukan dekomposisi menjadi subkriteria-subkriteria untuk pemilihan alternatif. Penentuan kriteria dan subkriteria berdasarkan studi literatur dan kemudian divalidasi oleh pakar sayur potong. Agregasi pendapat pakar dengan software Excel (Microsoft, 2013). Selanjutnya hasil agregasi diolah dengan software Superdecisions 2.2.6 berdasarkan perbandingan berpasangan. Perumusan alternatif strategi peningkatan dilakukan dengan penilaian bobot yang paling tinggi berdasarkan analisis $B O / C R$ untuk mengetahui tingkat pengaruhnya.

\section{Consistency Ratio (CR)}

Nilai consistency ratio (CR) dari setiap pakar harus lebih kecil dari 0,1. Apabila nilai CR lebih besar dari 0,1 , maka perlu dilakukan revisi terhadap penilaian yang dilakukan oleh pakar.

\section{Penggabungan Pendapat Pakar}

Agregat pendapat pakar digabungkan dengan menggunakan rata-rata geometrik (geometric mean) sebagai berikut:

$\overline{X_{G}}=\sqrt[n]{\prod_{i=1}^{n} X_{i}}$

Sumber: Marimin dan Maghfiroh (2010)

Keterangan:

$\overline{\boldsymbol{X}_{\boldsymbol{G}}} \quad=$ rata-rata geometrik

$\mathrm{n} \quad=$ jumlah responden

$\mathrm{X}_{\mathrm{i}} \quad=$ penilaian oleh responden ke-i

$\Pi \quad=$ perkalian

\section{Penentuan Responden}

Berdasarkan sumbernya, jenis data yang digunakan pada penelitian ini ialah data primer dan data sekunder. Data primer merupakan hasil pengamatan, wawancara, dan kuisioner terstruktur terhadap responden, sedangkan data sekunder diperoleh dari berbagai sumber, seperti penelitian terdahulu, jurnal, buku, dan dokumen dari berbagai instansi yang berhubungan dengan penelitian. Data yang digunakan dalam penelitian ini dikumpulkan melalui teknik pengumpulan data sebagai berikut:

1. Pengumpulan data primer melalui observasi lapangan, teknik wawancara mendalam (in-depth interview), dan pengisian kuesioner terstruktur dengan responden yang berkaitan dengan penelitian, dalam hal ini pakar dari PT SSS (manajemen); Institut Pertanian Bogor; IPB Agribusiness Development Station; Pusat Kajian Hortikultura IPB; Pusat Penelitian dan Pengembangan Hortikultura; dan UPT PTPH X Ciawi. 


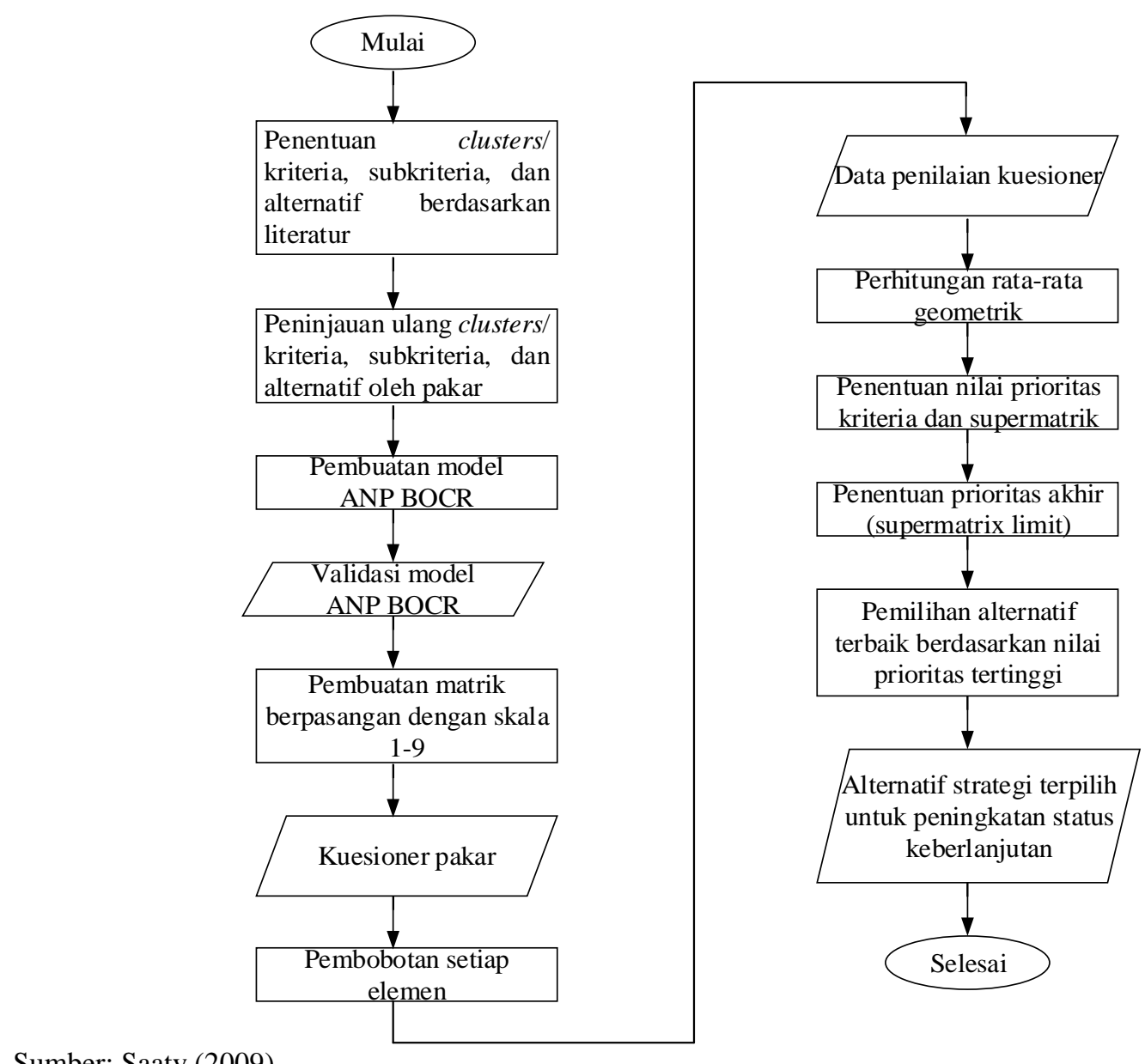

Sumber: Saaty (2009)

Gambar 1. Metode penelitian ANP BOCR

2. Pengumpulan data sekunder melalui studi pustaka, laporan-laporan dari lembaga terkait, dan literatur dari berbagai sumber. Penggunaan data sekunder seringkali harus divalidasi oleh pakar sayur potong, misalnya kriteria, subkriteria, dan ada tidaknya hubungan interdependencies (loop).

Metode pengambilan sampel dalam penelitian ini adalah purposive sampling dengan teknik judgemental sampling. Jumlah responden untuk penentuan struktur ANP BOCR sebanyak tiga orang, yaitu 2 pakar eksternal dan 1 pakar internal, sedangkan jumlah responden untuk analisis ANP BOCR sebanyak 5 orang, yaitu 1 orang responden internal dan 4 orang responden eksternal. Pakar tersebut merupakan akademisi, praktisi, dan pakar bidang hortikultura.

\section{HASIL DAN PEMBAHASAN}

\section{Struktur Analytic Network Process-Benefits Opportunities Costs Risks \\ Model ANP BOCR terdiri atas 4 kriteria} utama, yaitu benefits, opportunities, costs, dan risks. Sumber data yang menunjang kriteria utama disajikan dalam Tabel 1.
Setiap kriteria utama terdiri atas 4 kriteria, yaitu lingkungan, teknologi, kemitraan, dan ekonomi. Struktur ANP BOCR diperoleh berdasarkan literatur, hasil observasi di lapangan, dan diskusi dengan pakar sayur potong. Selanjutnya struktur ANP BOCR divalidasi oleh pakar ANP. Hal yang harus dihindari ketika membuat struktur ANP ialah jaringan yang terlalu kompleks (Dragoi, 2018).

Kriteria yang mempengaruhi keberlanjutan sayur potong ialah ekonomi, teknologi, kemitraan, dan lingkungan. Keberlanjutan ekonomi berfokus pada peningkatan profit petani mitra dan perusahaan (Aguado et al., 2016). Keberlanjutan teknologi berfokus pada penerapan teknologi yang dapat meningkatkan efisiensi produksi dan ramah terhadap lingkungan (James dan Ngarmsak, 2010). Keberlanjutan kemitraan berfokus pada petani mitra sebagai kelompok, bukan sebagai individu (UNIDROIT, FAO, IFAD, 2015). Keberlanjutan lingkungan berfokus pada menjaga ketersediaan pasokan sayuran yang merupakan bahan mentah sayur potong dengan mempertahankan kualitas lingkungan (Widiarini et al., 2009). 
Tabel 1. Sumber data yang menunjang kriteria utama

\begin{tabular}{lcc}
\hline Kriteria utama & Jenis data & Sumber data \\
\hline \multirow{2}{*}{ Benefits } & Primer & Pakar, petani mitra, dan PT SSS \\
& Sekunder & UNIDROIT, FAO, IFAD (2015) \\
Opportunities & Primer & Pakar, petani mitra, dan PT SSS \\
& Sekunder & James dan Ngarmsak (2010) \\
Costs & Primer & Pakar, petani mitra, dan PT SSS \\
& Sekunder & James dan Ngarmsak (2010) \\
Risks & Primer & Pakar, petani mitra, dan PT SSS \\
& Sekunder & James dan Ngarmsak (2010) \\
\hline
\end{tabular}

Alternatif strategi
keberlanjutan agroindustri sayur potong ialah
sebagai berikut:

a. Efisiensi Energi

Alternatif strategi efisiensi energi merupakan efisiensi penggunaan energi dan Sumber Daya Alam. Penghematan energi berupa bahan bakar transportasi dan penggunaan listrik yang merupakan sumber emisi karbon yang besar.

b. Teknologi Ramah Lingkungan

Alternatif strategi teknologi ramah lingkungan merupakan penerapan dan pengembangan teknologi ramah lingkungan yang mencakup on farm dan proses produksi sayur potong. Penerapan dan pengembangan teknologi ramah lingkungan on farm misalnya teknologi benih unggul yang mengurangi penggunaan pestisida kimia karena lebih resisten hama dan lebih produktif, dan juga agroforestri yang dapat mencegah erosi. Penerapan dan pengembangan teknologi ramah lingkungan pada proses pengolahan sayur potong, misalnya manajemen kontrol dosis disinfektan kimia sintetik, penggunaan bahan disinfektan yang ramah lingkungan, dan pengolahan limbah.Limbah yang dihasilkan sayur potong berupa limbah padat biomassa dan limbah cair.Limbah padat dapat dikomposkan, sedangkan limbah cair sebaiknya mendapatkan wastewater treatment (Peraturan Menteri Lingkungan Hidup Republik Indonesia No. 5 Tahun 2014) karena mengandung produk samping dari disinfektan klorin dioksida dan bahan organik.

c. Kemitraan

Alternatif strategi kemitraan dengan menerapkan area kemitraan yang lebih dekat dan pendampingan petani mitra berkelanjutan, bermanfaat mengurangi penggunaan bahan bakar yang merupakan emisi karbon dan juga mengurangi biaya transportasi. Area kemitraan yang lebih dekat juga akan menurunkan risiko kerusakan sayuran ketika pengiriman, terutama pembinaan petani mitra akan lebih intensif. Area kemitraan yang ditentukan harus sesuai spesifikasinya dengan jenis sayuran yang akan dibudidayakan.

d. Efisiensi Produksi

Alternatif strategi fisiensi produksi merupakan efisiensi produksi dan Supply Chain Management yang dilakukan dengan menerapkan Good Agriculture Practices dan Good Handling Practices yang baik sehingga meningkatkan kualitas sayuran yang berdampak jumlah rendemen meningkat dan otomatis jumlah limbah padat biomassa sayur potong menurun.

Gambar 2 merupakan model ANP BOCR yang terdiri atas 4 kriteria utama, yaitu benefits, opportunities, costs, dan risks. Setiap kriteria utama terdiri atas 4 kriteria, yaitu lingkungan, teknologi, kemitraan, dan ekonomi. Setiap kriteria memiliki subkriteria.

Subkriteria pada kriteria utama benefits dijelaskan sebagai berikut: Kriteria lingkungan, subkriterianya ialah ketersediaan energi dan sumber daya alam (a) dan pencegahan erosi (b), kriteria teknologi, subkriterianya ialah pengurangan penggunaan bahan kimia sintetik (c). Untuk kriteria kemitraan, subkriterianya ialah peningkatan keahlian petani mitra melalui kelompok tani (d), kriteria ekonomi, subkriterianya ialah peningkatan keuntungan petani mitra (e), dan peningkatan keuntungan perusahaan (f).

Subkriteria pada kriteria utama opportunities dijelaskan sebagai berikut: kriteria lingkungan, subkriterianya ialah agribisnis ramah lingkungan (g), kriteria teknologi, subkriterianya ialah benih unggul (h), infrastruktur pengolahan limbah (i). Untuk kriteria kemitraan, subkriterianya ialah peningkatan permintaan bahan baku [bagi perusahaan] (j). peningkatan keterjaminan pasar [bagi petani mitra] (k), kriteria ekonomi, subkriterianya ialah peningkatan mutu bahan baku dan produk (1), peningkatan rendemen bahan baku,, (m), dan peningkatan produktivitas (n).

Subkriteria pada kriteria utama costs dijelaskan sebagai berikut: kriteria lingkungan, subkriterianya ialah biaya perbaikan lingkungan (o), kriteria teknologi, subkriterianya ialah biaya riset dan pengembangan (p) dan biaya instalasi pengolahan limbah (q). Untuk kriteria kemitraan, subkriterianya ialah biaya pelatihan dan penyuluhan teknologi ramah lingkungan (r). Untuk kriteria ekonomi, subkriterianya ialah biaya produksi on farm (s), biaya produksi di perusahaan (t), dan biaya transportasi $(\mathrm{u})$. 


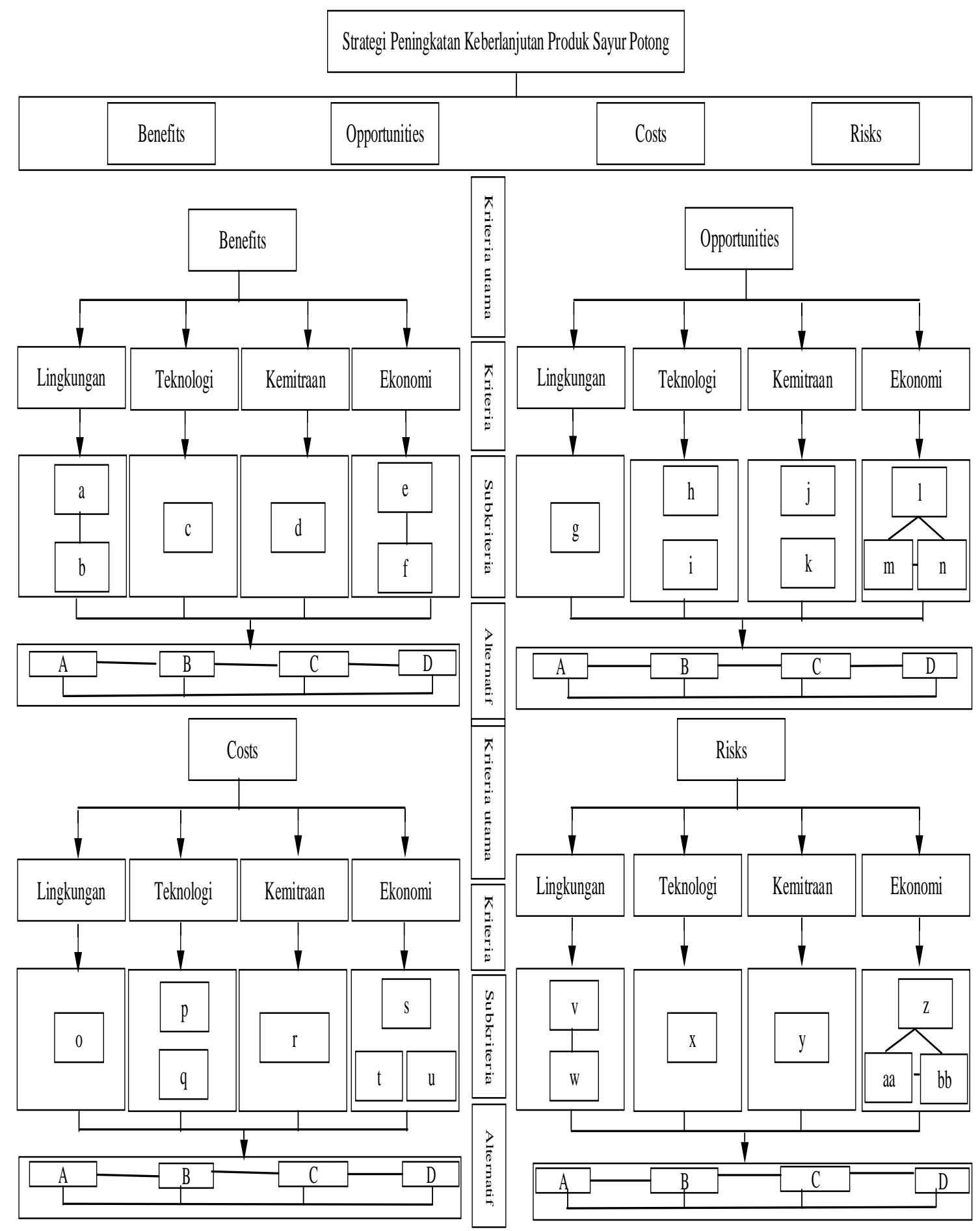

Gambar 2. Struktur ANP pemilihan alternatif peningkatan keberlanjutan produk sayur potong

Subkriteria pada kriteria utama risks dijelaskan sebagai berikut: Untuk kriteria lingkungan, subkriterianya ialah pencemaran lingkungan (v) dan penurunan keberlanjutan usaha (w). Untuk kriteria teknologi, subkriterianya ialah keterbatasan teknologi (x). Untuk kriteria kemitraan, subkriterianya ialah pelanggaran perjanjian kemitraan (y). Untuk kriteria ekonomi, subkriterianya ialah penurunan produksi dan produktivitas (z), penurunan mutu bahan baku dan produk (aa), dan penurunan profit (bb).
Alternatif strategi pada Gambar 2 terdiri atas efisiensi energi (A), teknologi ramah lingkungan (B), kemitraan (C), dan efisiensi produksi (D).

\section{Prioritas Strategi Peningkatan Keberlanjutan Sayur Potong}

Tabel 2 menunjukkan bobot kriteria utama, kriteria, dan subkriteria pada ANP BOCR. Benefits merupakan kriteria yang memiliki bobot tertinggi, yaitu 0,3952 . 
Tabel 3 menunjukkan bobot global untuk kriteria utama dan kriteria. Kriteria utama benefits memiliki bobot global tertinggi sehingga benefits merupakan kriteria utama yang paling mempengaruhi keberlanjutan produk sayur potong. Kriteria ekonomi memiliki bobot global tertinggi sehingga ekonomi merupakan kriteria yang paling mempengaruhi keberlanjutan produk sayur potong.

Tabel 4 menunjukkan bobot global subkriteria yang diperoleh dari perkalian bobot global kriteria dengan bobot subkriteria, sedangkan bobot global kriteria diperoleh dari perkalian bobot kriteria dengan bobot kriteria utama. Ketiga subkriteria yang memiliki bobot global tertinggi ialah peningkatan keuntungan petani mitra, peningkatan keuntungan perusahaan, dan peningkatan keahlian petani mitra melalui kelompok tani. Ketiga subkriteria tersebut berada pada kriteria utama benefits sehingga sesuai dengan analisis ANP BOCR yang menyatakan bahwa benefits merupakan kriteria utama yang paling berpengaruh. Peningkatan keuntungan petani mitra dan peningkatan keuntungan perusahaan merupakan subkriteria pada dimensi ekonomi dalam kriteria utama benefit, sedangkan peningkatan keahlian petani mitra melalui kelompok tani merupakan subkriteria pada dimensi kemitraan dalam kriteria utama benefits.

Tabel 2. Bobot kriteria utama, kriteria, dan subkriteria pada ANP BOCR

\begin{tabular}{|c|c|c|c|c|}
\hline \multirow{3}{*}{$\begin{array}{l}\text { Kriteria utama } \\
\text { BENEFITS } \\
(0,3952)\end{array}$} & \multicolumn{2}{|c|}{ Kriteria } & \multicolumn{2}{|l|}{ Subkriteria } \\
\hline & & & Peningkatan keuntungan perusahaan & 0,4869 \\
\hline & Ekonom1 & 0,5056 & Peningkatan keuntungan petani mitra & 0,5131 \\
\hline & Kemitraan & 0,2151 & $\begin{array}{l}\text { Peningkatan keahlian petani mitra melalui } \\
\text { kelompok tani }\end{array}$ & 1,0000 \\
\hline & & 01264 & Ketersediaan energi dan sumber daya alam & 0,5043 \\
\hline & Lingkungan & 0,1264 & Pencegahan erosi & 0,4957 \\
\hline & Teknologi & 0,1529 & Pengurangan penggunaan bahan kimia sintetik & 1,0000 \\
\hline \multirow{8}{*}{$\begin{array}{l}\text { OPPORTUNITIES } \\
(0,1976)\end{array}$} & \multirow{3}{*}{ Ekonomi } & \multirow{3}{*}{0,2500} & Peningkatan mutu bahan baku dan produk & 0,3356 \\
\hline & & & Peningkatan produktivitas & 0,3311 \\
\hline & & & Peningkatan rendemen bahan baku & 0,3332 \\
\hline & \multirow{2}{*}{ Kemitraan } & \multirow{2}{*}{0,2500} & Peningkatan keterjaminan pasar & 0,4660 \\
\hline & & & Peningkatan permintaan bahan baku & 0,5340 \\
\hline & Lingkungan & 0,2500 & Agribisnis ramah lingkungan & 1,0000 \\
\hline & \multirow{2}{*}{ Teknologi } & \multirow{2}{*}{0,2500} & Benih unggul & 0,5848 \\
\hline & & & Infrastruktur pengolahan limbah & 0,4152 \\
\hline \multirow{7}{*}{$\begin{array}{l}\text { COSTS } \\
(0,2390)\end{array}$} & \multirow{3}{*}{ Ekonomi } & \multirow{3}{*}{0,3629} & Biaya produksi di perusahaan & 0,3674 \\
\hline & & & Biaya produksi on farm & 0,3572 \\
\hline & & & Biaya transportasi & 0,2754 \\
\hline & Kemitraan & 0,1480 & $\begin{array}{l}\text { Biaya pelatihan dan penyuluhan teknologi } \\
\text { Ramah lingkungan }\end{array}$ & 1,0000 \\
\hline & Lingkungan & 0,1630 & Biaya perbaikan lingkungan & 1,0000 \\
\hline & \multirow{2}{*}{ Teknologi } & \multirow{2}{*}{0,3261} & Biaya instalasi pengolahan limbah & 0,5888 \\
\hline & & & Biaya riset dan pengembangan & 0,4112 \\
\hline RISKS & \multirow{3}{*}{ Ekonomi } & \multirow{3}{*}{0,3713} & Penurunan mutu bahan baku dan produk & 0,3333 \\
\hline \multirow[t]{6}{*}{$(0,1682)$} & & & Penurunan produksi dan produktivitas & 0,3333 \\
\hline & & & Penurunan profit & 0,3333 \\
\hline & Kemitraan & 0,1635 & Pelanggaran perjanjian kemitraan & 1,0000 \\
\hline & \multirow{2}{*}{ Lingkungan } & \multirow{2}{*}{0,1827} & Pencemaran lingkungan & 0,5000 \\
\hline & & & Penurunan keberlanjutan usaha & 0,5000 \\
\hline & Teknologi & 0,2825 & Keterbatasan teknologi & 1,0000 \\
\hline
\end{tabular}

Tabel 3. Bobot global kriteria utama dan kriteria

\begin{tabular}{lccc}
\hline Kriteria utama & Bobot global & Kriteria & Bobot global \\
\hline Benefits & 0,3952 & Ekonomi & 0,3984 \\
Opportunities & 0,1976 & Kemitraan & 0,1973 \\
Costs & 0,2390 & Lingkungan & 0,1691 \\
Risks & 0,1682 & Teknologi & 0,2353 \\
\hline Total & 1,0000 & Total & 1,0000 \\
\hline
\end{tabular}


Subkriteria yang memiliki bobot global tertinggi untuk masing-masing kriteria utama ialah sebagai berikut: peningkatan keuntungan petani mitra (benefits), agribisnis ramah lingkungan (opportunities), biaya instalasi pengolahan limbah (costs), dan keterbatasan teknologi (risks). Terlihat bahwa strategi kemitraan merupakan prioritas strategi karena memiliki keuntungan dalam meningkatkan keuntungan petani mitra dan berpeluang menjadi agribisnis yang ramah lingkungan, walaupun dalam aspek biaya mengalami biaya instalasi pengolahan limbah, atau pun dalam aspek risiko mengalami keterbatasan teknologi.

Tabel 4. Bobot global subkriteria

\begin{tabular}{|c|c|c|c|c|c|c|}
\hline $\begin{array}{l}\text { Kriteria } \\
\text { utama }\end{array}$ & Kriteria & $\begin{array}{c}\text { Bobot } \\
\text { kriteria }\end{array}$ & $\begin{array}{c}\text { Bobot global } \\
\text { kriteria }\end{array}$ & Subkriteria & $\begin{array}{c}\text { Bobot } \\
\text { subkriteria }\end{array}$ & $\begin{array}{c}\text { Bobot global } \\
\text { subkriteria }\end{array}$ \\
\hline \multirow{4}{*}{ Benefits } & Ekonomi & 0,5056 & 0,1998 & $\begin{array}{l}\text { Peningkatan Keuntungan } \\
\text { Petani Mitra } \\
\text { Peningkatan Keuntungan } \\
\text { Perusahaan }\end{array}$ & $\begin{array}{l}0,5131 \\
0,4869\end{array}$ & $\begin{array}{l}\mathbf{0 , 1 0 2 5} \\
0,0973\end{array}$ \\
\hline & Kemitraan & 0,2151 & 0,0850 & $\begin{array}{l}\text { Peningkatan Keahlian } \\
\text { Petani Mitra melalui } \\
\text { Kelompok Tani } \\
\end{array}$ & 1,0000 & $\mathbf{0 , 0 8 5 0}$ \\
\hline & Teknologi & 0,1529 & 0,0604 & $\begin{array}{l}\text { Pengurangan Penggunaan } \\
\text { Bahan Kimia Sintetik } \\
\end{array}$ & 1,0000 & 0,0604 \\
\hline & Lingkungan & 0,1264 & 0,0500 & $\begin{array}{l}\text { Ketersediaan Energi dan } \\
\text { Sumber Daya Alam } \\
\text { Pencegahan Erosi } \\
\end{array}$ & $\begin{array}{l}0,5043 \\
0,4957 \\
\end{array}$ & $\begin{array}{l}0,0252 \\
0,0248 \\
\end{array}$ \\
\hline \multirow{5}{*}{ Opportunities } & Ekonomi & 0,2500 & 0,0494 & $\begin{array}{l}\text { Peningkatan Mutu Bahan } \\
\text { Baku dan Produk } \\
\text { Peningkatan Rendemen } \\
\text { Bahan Baku } \\
\text { Peningkatan Produktivitas }\end{array}$ & $\begin{array}{l}0,3356 \\
0,3332 \\
0,3311\end{array}$ & $\begin{array}{l}0,0166 \\
0,0165 \\
0,0164\end{array}$ \\
\hline & Kemitraan & 0,2500 & 0,0494 & $\begin{array}{l}\text { Peningkatan Permintaan } \\
\text { Bahan Baku } \\
\text { Peningkatan Keterjaminan } \\
\text { Pasar }\end{array}$ & $\begin{array}{l}0,5340 \\
0,4660 \\
\end{array}$ & $\begin{array}{l}0,0264 \\
0,0230 \\
\end{array}$ \\
\hline & \multirow[b]{2}{*}{ Teknologi } & 0,2500 & \multirow[b]{2}{*}{0,0494} & Benih Unggul & 0,5848 & 0,0289 \\
\hline & & 0,2500 & & $\begin{array}{l}\text { Infrastruktur Pengolahan } \\
\text { Limbah }\end{array}$ & 0,4152 & 0,0205 \\
\hline & Lingkungan & 0,2500 & 0,0494 & $\begin{array}{l}\text { Agribisnis Ramah } \\
\text { Lingkungan }\end{array}$ & 1,0000 & 0,0494 \\
\hline \multirow{4}{*}{ Costs } & Ekonomi & 0,3629 & 0,0867 & $\begin{array}{l}\text { Biaya Produksi di } \\
\text { Perusahaan } \\
\text { Biaya Produksi On Farm } \\
\text { Biaya Transportasi } \\
\end{array}$ & $\begin{array}{l}0,3674 \\
0,3572 \\
0,2754 \\
\end{array}$ & $\begin{array}{l}0,0319 \\
0,0310 \\
0,0239 \\
\end{array}$ \\
\hline & Kemitraan & 0,1480 & 0,0354 & $\begin{array}{l}\text { Biaya Pelatihan dan } \\
\text { Penyuluhan Teknologi } \\
\text { Ramah Lingkungan }\end{array}$ & 1,0000 & 0,0354 \\
\hline & Teknologi & 0,3261 & 0,0779 & $\begin{array}{l}\text { Biaya Instalasi Pengolahan } \\
\text { Limbah } \\
\text { Biaya Riset dan } \\
\text { Pengembangan }\end{array}$ & $\begin{array}{l}0,5888 \\
0,4112 \\
\end{array}$ & $\begin{array}{l}0,0459 \\
0,0321 \\
\end{array}$ \\
\hline & Lingkungan & 0,1630 & 0,0390 & $\begin{array}{l}\text { Biaya Perbaikan } \\
\text { Lingkungan }\end{array}$ & 1,0000 & 0,0390 \\
\hline \multirow{5}{*}{ Risks } & Ekonomi & 0,3713 & 0,0624 & $\begin{array}{l}\text { Penurunan Mutu Bahan } \\
\text { Baku dan Produk } \\
\text { Penurunan Produksi dan } \\
\text { Produktivitas } \\
\text { Penurunan Profit }\end{array}$ & $\begin{array}{l}0,3333 \\
0,3333\end{array}$ & $\begin{array}{l}0,0208 \\
0,0208 \\
0,0208\end{array}$ \\
\hline & Kemitraan & 0,1635 & 0,0275 & $\begin{array}{l}\text { Pelanggaran Perjanjian } \\
\text { Kemitraan }\end{array}$ & 1,0000 & 0,0275 \\
\hline & Teknologi & 0,2825 & 0,0475 & Keterbatasan Teknologi & 1,0000 & 0,0475 \\
\hline & \multirow[t]{2}{*}{ Lingkungan } & \multirow[t]{2}{*}{0,1827} & 0,0307 & $\begin{array}{l}\text { Pencemaran Lingkungan } \\
\text { Penurunan Keberlanjutan } \\
\text { Usaha }\end{array}$ & $\begin{array}{l}0,5000 \\
0,5000 \\
\end{array}$ & 0,0154 \\
\hline & & & 1,0000 & & & 1,0000 \\
\hline
\end{tabular}


Tabel 5 menunjukkan bobot alternatif strategi berdasarkan kriteria utama. Terlihat bahwa alternatif strategi kemitraan memiliki nilai tertinggi baik untuk bobot alternatif strategi berdasarkan kriteria utama benefits, opportunities, costs, dan risks, maupun bobot globalnya.

Tingkat prioritas alternatif strategi ditunjukkan pada Tabel 6. Berdasarkan rasio $\mathrm{BO} / \mathrm{CR}$, alternatif strategi terpilih ialah kemitraan (area kemitraan yang lebih dekat dan pendampingan petani mitra berkelanjutan). Bahan bakar transportasi merupakan sumber emisi karbon yang besar dalam industri sayur potong (James dan Ngarmsak, 2010) sehingga pemindahan area kemitraan dapat mengurangi emisi karbon. Emisi rantai pasok memang merupakan emisi karbon yang besar dalam produksi makanan sehingga perlu dilakukan penerapan teknologi budidaya yang ramah lingkungan (Audsley et al., 2009). Dengan pendampingan petani mitra berkelanjutan, dapat dicapai efisiensi produksi dengan cara mereduksi limbah yang ditimbulkan dari proses tersebut (Darmawan et al.,2012).

Prioritas alternatif strategi tersebut sesuai dengan ketiga subkriteria yang memiliki bobot global tertinggi, yaitu peningkatan keahlian petani mitra melalui kelompok tani, peningkatan keuntungan petani mitra, dan peningkatan keuntungan perusahaan (Tabel 4). Dengan menerapkan strategi kemitraan, dapat meningkatkan keahlian petani mitra melalui kelompok tani, meningkatkan keuntungan petani mitra, dan meningkatkan keuntungan perusahaan.

\section{Implikasi Manajerial}

Berdasarkan analisis ANP BOCR, alternatif strategi prioritas ialah kemitraan (area kemitraan yang lebih dekat dan pendampingan petani mitra berkelanjutan). Industri sayur potong mengadakan kemitraan di area yang jauh dari lokasi industri sayur potong karena kualitas hasil budidaya sayur yang memenuhi spesifikasi dan untuk menjaga kestabilan jumlah pasokan. Di sisi lain, bahan bakar akibat jarak merupakan sumber emisi karbon yang besar dalam industri sayur potong (James dan Ngarmsak, 2010) sehingga pakar merekomendasikan pemindahan kemitraan. Jarak yang jauh juga meningkatkan risiko kerusakan suplai sayur, yaitu tumbukan antara sayuran atau antara sayuran dengan peti kemas. Dengan area kemitraan yang lebih dekat dan pendampingan mitra berkelanjutan, tidak hanya mengurangi emisi karbon, biaya transportasi, dan risiko kerusakan suplai sayuran, tetapi lebih praktis dalam membina petani mitra secara berkelanjutan. Pendampingan petani mitra berkelanjutan sangat penting karena industri sayur potong tidak memiliki lahan pertanian sehingga tergantung pada kemitraan.

Tabel 5. Bobot alternatif strategi

\begin{tabular}{llcc}
\hline Kriteria utama & \multicolumn{1}{c}{ Alternatif strategi } & Bobot alternatif strategi & Bobot global \\
\hline Benefits & Kemitraan & 0,3116 & 0,1231 \\
& Efisiensi energi & 0,2417 & 0,0955 \\
& Efisiensi produksi & 0,2246 & 0,0888 \\
& Teknologi ramah lingkungan & 0,2221 & 0,0878 \\
\hline Opportunities & Kemitraan & 0,2672 & 0,0528 \\
& Efisiensi energi & 0,2467 & 0,0488 \\
& Efisiensi produksi & 0,2305 & 0,0456 \\
& Teknologi ramah lingkungan & 0,2556 & 0,0505 \\
\hline Costs & Kemitraan & 0,2597 & 0,0621 \\
& Efisiensi energi & 0,2562 & 0,0612 \\
& Efisiensi produksi & 0,2287 & 0,0547 \\
& Teknologi ramah lingkungan & 0,2554 & 0,0610 \\
\hline Risks & Kemitraan & 0,2706 & 0,0455 \\
& Efisiensi energi & 0,2631 & 0,0442 \\
& Efisiensi produksi & 0,2309 & 0,0388 \\
& Teknologi ramah lingkungan & 0,2355 & 0,0396 \\
\hline
\end{tabular}

Tabel 6. Hasil rasio BO/CR

\begin{tabular}{lcccccc}
\hline \multirow{2}{*}{ Alternatif strategi } & \multicolumn{4}{c}{ Bobot global } & Hasil rasio & \multirow{2}{*}{ Peringkat } \\
\cline { 2 - 5 } & $\mathbf{B}$ & $\mathbf{O}$ & $\mathbf{C}$ & $\mathbf{R}$ & BO/CR & \\
\hline Kemitraan & 0,1231 & 0,0528 & 0,0621 & 0,0455 & 2,3018 & 1 \\
Efisiensi produksi & 0,0888 & 0,0456 & 0,0547 & 0,0388 & 1,9049 & 2 \\
Teknologi ramah lingkungan & 0,0878 & 0,0505 & 0,0610 & 0,0396 & 1,8343 & 3 \\
Efisiensi energi & 0,0955 & 0,0488 & 0,0612 & 0,0442 & 1,7188 & 4 \\
\hline
\end{tabular}


Sebelum dilakukan pemindahan kemitraan sebaiknya dilakukan analisis kesesuaian lahan (Wibowo, 2008; Saida, 2011). Selanjutnya, dilakukan penerapan pilot plant untuk memastikan apakah lahan tersebut sesuai untuk produk unggulan seperti paprika, lettuce head, dan brokoli, misalnya ketinggian lahan dan jenis tanah.

Untuk menerapkan prioritas strategi tersebut, maka hal yang harus disiapkan ialah sebagai berikut:

\section{Secara Internal}

Hal yang harus disiapkan secara internal di daerah kemitraan yang baruialah ruang penerimaan produk budidaya, ruang penyimpanan berpendingin, dan alat timbang. Seringkali petani mitra memanen dengan jumlah yang melebihi jumlah yang telah disepakati dan memaksa pihak perusahaan untuk tetap mengangkut hasil panennya. Hal tersebut menyebabkan tumpukan produk hasil budidaya yang terlalu tinggi dan berdesakkan pada peti kemas berlubang (perforated container) yang tidak sesuai dengan Standard Operating Procedure sehingga menyebabkan kerusakan produk. Ruang penyimpanan berpendingin meminimalisir risiko kerusakan produk. Alat timbangan perlu diadakan di area kemitraan yang baruagar tidak terjadi kekeliruan pencatatan berat produk hasil budidaya.

\section{Secara Eksternal}

Hal yang harus disiapkan dengan stakeholder ialah sosialisasi pentingnya kemitraan, yaitu menerapkan area kemitraan yang lebih dekat dan pendampingan petani mitra berkelanjutan. Dengan sosialisasi, stakeholder dapat memahami bahwa prioritas kebijakan ini penting untuk diterapkan demi keberlanjutan produk sayur potong.

Hal yang harus disiapkan dengan petani mitra ialah penyuluhan pertanian secara intensif untuk mencapai produktivitas hijau dengan penerapan Good Agriculture Practices (Peraturan Menteri Pertanian Nomor 48 Tahun 2009) dan Good Handling Practices (Peraturan Menteri Pertanian Republik Indonesia Nomor 44 Tahun 2009). Penanaman dan pemanenan harus dilakukan sesuai dengan jadwal yang ditetapkan perusahaan.Untuk menciptakan komunikasi yang baik antara pihak petani mitra dan perusahaan, perlu membuat grup WhatApps yang responsif.

\section{Keterbatasan Penelitian}

Keunggulan penelitian ini ialah strategic effect yang berarti penerapan strategi akan memberikan dampak, namun kelemahan penelitian ini ialah hasil analisis ANP BOCR belum dapat menjawab masalah pembuangan air limbah yang dilakukan PT SSS.

\section{KESIMPULAN DAN SARAN}

\section{Kesimpulan}

Struktur penentuan strategi peningkatan keberlanjutan sayur potong merupakan struktur yang kompleks karena terdiri atas 4 kriteria utama, 4 kriteria, 28 subkriteria, dan 4 alternatif strategi. Beberapa subkriteria dan keempat alternatif strateginya memiliki hubungan interdependencies dan membentuk hubungan loop. Oleh karena itu, metode yang sesuai ialah ANP BOCR yang unggul dalam mengatasi masalah kompleks.

Alternatif strategi terbaik ialah kemitraan (area kemitraan yang lebih dekat dan pendampingan petani mitra berkelanjutan) yang berpotensi mengurangi emisi karbon, biaya transportasi, kerusakan suplai sayur, dan meningkatkan keahlian petani mitra dalam menerapkan Good Agriculture Practice dan Good Handling Practice.

Walaupun Peraturan Menteri Lingkungan Hidup Republik Indonesia No. 5 Tahun 2014 menyatakan industri pengolahan sayuran harus memberikan perlakuan pada air limbahnya, tapi masalah pembuangan air limbah sayur potong yang mengandung disinfektan kimia bukan merupakan prioritas dalam peningkatan keberlanjutan sayur potong berdasarkan pengurangan emisi karbon karena emisi karbon disinfektan kimia jauh lebih kecil dibandingkan emisi karbon bahan bakar.

\section{Saran}

Untuk melaksanakan strategi prioritas, maka diperlukan kerjasama antara pelaku usaha, universitas, dan balai penelitianagar terjadi sinergi peningkatan keberlanjutan.

\section{DAFTAR PUSTAKA}

Aguado SH, Segado IS, dan Pitcher TJ. 2016. Towardssustainable fisheries: amulti-criteria parcipatory approach to assesing indicators of sustainable fishing communities: acase study from Cartagena (Spain). Marine Policy. 65: 97-106.

Audsley E, Brander M, Chatterton J, MurphyBokern D, Webster C, Williams A. 2009. How low can we go? An assesment of greenhouse gas emissions from the UK food system end and the scope to reduce them by 2050. Food Climate Research Network. London: WWF.

[BPS] Biro Pusat Statistik. 2016. Konsumsi Buah dan Sayur Susenas Maret 2016. Jakarta: BPS.

[BPS] Biro Pusat Statistik. 2017. Statistik Indonesia. Jakarta: BPS.

Darmawan MA, Wiguna B, Marimin, Machfud. 2012. Peningkatan produktivitas proses produksi karet alam dengan pendekatan green productivity. Jurnal Teknologi Industri Pertanian. 22 (2): 98-105. 
Dragoi M. 2018. Joining or not joining nonindustrial private forests into a single management unite: acase-study shaped as an Analytic Network Process. Forest Policy and Economics. 89: 63-70.

Gonzalez EDRS, Sarkis J, Huisingh D, Huatuco LH, Maculan N, Montoya-Torres JR, de Almeida CMVB. 2015. Making real progress toward more sustainable societies using decision support models and tools: introduction to the special volume. Journal Cleaner Production. 105: 1-13.

Gorener A. 2012. Comparing AHP and ANP: an application of strategic decisions making in a manufacturing company. IJBSS. 3 (11) : 194208.

Ikatrinasari ZF, Maarif S, dan Sa'id EG. 2011. Model pemilihan kelembagaan agropolitan berbasis groindustri dengan Analytical Network Process. Jurnal Teknologi Industri. 19 (3): 130-137.

[IPFA] International Fresh-cut Produce Association. About IFPA. Tersedia dari:http://www.creativew.com/sites/ifpa/fcf. html. 2017.02.021.

Jaafari A, Najafi A, dan Melon MG. 2015. Decisionmaking for the selection of a best wood extraction method: an Analytic Network Process approach. Forest Policy and Economics. 50: 200-2009.

James JB dan Ngarmsak T. 2010. Processing of fresh-cut tropical fruits and vegetables: a technical guide.Bangkok:FAO.

Marimin dan Maghfiroh N. 2010. Aplikasi Teknik Pengambilan Keputusan dalam Manajemen Rantai Pasok. Bogor: IPB Press.

Martin-Belloso O, dan Soliva-Fortuny R. 2011. Advances in Fresh-cut Fruits and Vegetables Processing. New York: CRC Press.

Medel-Gonzalez F, Salomon VAP, Garcia-Avila L, Hernandez C. 2014. Multicriteria sustainability performance measurement: ANP Cuban application. International Symposium of the Analytic Hierarchy Process. Washington DC, the United States. 29 Juni-2 Juli 2014.

Murti A, Marimin, dan Arkeman Y. 2015. Peningkatan kinerja karyawan bagian trade operations studi kasus Bank OCBC NISP. JABM. 1 (1): 34-45.
Persada C, Sitorus SRP, Marimin, Djakapermana RD. 2015. Determination sustainability status in urban infrastructure and policy recommendation for development case study: Bandarlampung City, Indonesia. Civil and Environmental Research. 6 (12): 49-60.

Saaty TL. 2009. Theory and Applications of the Analytic Network Process: Decision Making with Benefits, Opportunities, Costs, and Risks. Pittsburgh: RWS Publications.

Sato Y, Tan KH, dan Tse YK. 2017. Investment performance analysis of industrial products: case of an effluent processing facility at a chemical company. International Journal of Production Economics. 194: 52-58.

Sultan A dan Saurabh. 2013. Achieving sustainable development through value chain. IJMVSC.4 (2): $39-46$

[UNIDROIT, FAO, IFAD] the International Institute for the Unification of Private Law, the Food and Agricultural Organization of the United Nations, the International Fund for Agricultural Development. 2015. Legal guide on contract farming.Tersedia dari:www.fao.org/3/ai4756e.pdf.2017.12.001.

Wibowo S. 2008. Model pengelolaan usaha tani sayuran dataran tinggi berkelanjutan di Kawasan Agropolitan. [Disertasi]. Bogor: Institut Pertanian Bogor.

Widiarini R, Sabiham S, Sutjahjo SH, Las I. 2009. Sustainability analysis of existing agriculture on high risk erosion area: case studies in Lembang, West Bandung District and Dongko, Trenggalek District. Journal Soil and Climate. 29: 65-80.

[WEF] World Economic Forum. 2014. Defining sustainable competitiveness. Tersedia dari: http://reports.weforum.org/globalcompetitiveness-report-2014-2015/definingsustainable-competitiveness/. 2017.02.027.

Xu Y, Zhang L, Yeh C, Liu Y. 2018. Evaluating WEEE recycling innovation strategies with interacting sustainability-related criteria. Journal Cleaner Production. 190: 618-629. 